\title{
Los contenidos curriculares en las fotografías delos libros de texto de Educación Física en Secundaria Curricular contents in the photographs of secondary-level Physical Education textbooks

\author{
Alba González-Palomares, Ana Rey-Cao \\ Universidade de Vigo
}

\begin{abstract}
Resumen. El objetivo del trabajo es analizar si los libros de texto de Educación Física «EF», publicados a partir de la Ley Orgánica 2/2006, de 3 de mayo, de Educación -LOE- para la Educación Secundaria Obligatoria «ESO», muestran desequilibrios en la representación de las diferentes actividades físicas que se proponen en los bloques de contenidos del currículo. En el presente estudio se exponen los resultados del análisis de ocho libros. Un total de 539 fotografías pertenecientes a las editoriales Anaya y Bruño: Pila Teleña. Para el análisis de contenido de las imágenes se utilizó un instrumento de observación elaborado ad hoc. La prueba piloto, la consulta a expertos/as y la triangulación con observadores/as son algunos de los criterios de cientificidad que avalan el instrumento. Los resultados muestran que las imágenes mayoritarias son las referidas al bloque de contenidos de «Juegos y deportes», y a modelos de actividad física deportivos alejados de la competición y del alto rendimiento, tendencia que ya había sido identificada en los contenidos visuales de la LOGSE.
\end{abstract}

Palabras clave. libro de texto, educación física, foto, análisis de contenido, programa de estudios.

Abstract. The objective of the study is to analyze whether the Physical Education «PE» textbooks published under the legal framework of LOE «Organic Law of Education -2/2006, $3^{\text {rd }}$ May», for the Secondary Obligatory Education «ESO» show imbalances in the representation of different physical activities offered in curriculum content blocks. This study presents the results of the analyses of eight books. A total of 539 photographs from the Anaya and Bruño: Pila Teleña publishing companies. An ad hoc observation tool was used for the analysis of image content. Pilot testing, consulting with experts and triangulation with observers are some of the validity criteria that support the instrument. The results show that the images are mostly related to the «Games and Sports» content block and to physical activity and sport models not related to high performance competitions, trend which was already identified in the visual contents of the previous legal framework LOGSE.

Keywords. textbook, physical education, photography, content analysis, curriculum.

\section{Introducción}

El libro de texto escolar es una herramienta de trabajo para el docente, un recurso didáctico facilitador de la asimilación de conocimientos para el alumnado, y un recurso material de especificidad formal (Martínez, 2002). Una de las características que le otorga especial relevancia es su familiaridad. Padres y madres, alumnado, docentes y personal directivo, tienen normalizado este objeto de la vida escolar (Moray, 2010). Todo ello hace que el libro de texto desarrolle un papel importante en el sistema educativo y que sea necesario prestarle una especial atención para evaluar los conocimientos que le transmite al alumnado.

Los elementos fundamentales en la creación de los libros de texto son tres: el personal experto que se ocupa de recortar la realidad y escolarizarla, las jurisdicciones que controlan los contenidos a enseñar en el aula, y las editoriales que diseñan y colocan el producto en el mercado. Los materiales curriculares utilizados tradicionalmente en la EF escolar han sido los materiales de carácter físico-deportivo -tales como pelotas, colchonetas y otro material deportivo- ligados directamente al desarrollo de las actividades prácticas. Una serie de factores internos y externos han propiciado un incremento en la producción de libros de texto y unidades didácticas para la EF. Entre los internos destaca la normalización curricular alcanzada con la aparición de la LOGSE de 1990. Como factores externos se presentan los intereses económicos de las editoriales que han visto en la EF un mercado todavía sin explotar (Molina, Devís \& Peiró, 2008).

La Ley Orgánica 2/2006, de 3 de mayo, de Educación establece el marco legal en el que se editan los libros de texto analizados en este trabajo. El Real Decreto 1631/2006, de 29 de diciembre desarrolla la ordenación y establece el currículo de la ESO y, dentro de éste, el currículum de EF de esta etapa educativa. En ambos documentos, los contenidos se organizan alrededor de cuatro grandes bloques: bloque 1 . Condición física y salud; bloque 2. Juegos y deportes; bloque 3. Expresión corporal; y bloque 4. Actividades en el medio natural ${ }^{1}$.

A pesar de esta especificación curricular formal, la práctica docente en la EF se caracteriza por el predominio de contenidos que desarrollan

Fecha recepción: 07-02-14- Fecha envío revisores: 09-02-14- Fecha de aceptación: 06-06-14 Alba Gonźlez-Palomares

albagonzalez@uvigo.es la eficacia motrizy la instrumentalización del cuerpo. La actual educación física escolar está drenada por el fenómeno deportivo (Barbero, 1996). El proceso deportivizador (Lagardera, 1992) ha influido en el espectro de expresiones motrices que se desarrollan en la EF escolar, con un absoluto dominio de los deportes sobre el resto de contenidos (Canales \& Rey, 2008). Por otra parte la instrumentalización ha sido definida por Puig y Heinemann (1991) como el modelo de actividad física contemporánea que se asocia con empresas comerciales que disponen de sofisticada maquinaria que permite el cultivo del cuerpo en aras a darle una forma más acorde al modelo de cuerpo demandado por la sociedad. La actividad física es un producto que se vende para satisfacer las necesidades de los clientes. La preocupación prioritaria por los problemas de sobrepeso y la obesidad en las sociedades del capitalismo tardío (Kogan, 2003; Walder, 2004; World Health Organitation(WHO), 2002) inclina a la educación física hacia su instrumentalización como una «biotecnología» (Pringle \& Pringle, 2012; Tinning, 2012) capaz de solventar estos problemas (Camacho-Miñano, Fernández, Ramírez \& Blández, 2013; Santos, 2005). La política del cuerpo es coordinada por un conjunto enormemente complejo de mecanismos de poder, controles recíprocos, ajustes, que distribuyen e instauran sutilmente las piezas de un cuerpo sometido que hace lo que se desea de él (Foucault, 1992). La disposición adicional cuarta de la Ley Orgánica 8/2013, de9 de diciembre, para la mejora de la calidad educativa-LOMCE-sobre la «Promoción de la actividad física y dieta equilibrada» es una evidencia de la presión ejercida por el Ministerio de Sanidad sobre el ministerio educativo (Europapress, 2012; Ministerio de Sanidad, Servicios Sociales e Igualdad, 2014). La medida, vacía de contenido pedagógico explícito, se instaura con una finalidad estrictamente higienista: «Las Administraciones educativas adoptarán medidas para que la actividad física y la dieta equilibrada formen parte del comportamiento infantil y juvenil» ${ }^{2}$

El paradigma de la «actividad física para la salud» penetra con fuerza en el discurso de la actual EF escolar, y se convierte en su argumento salvavidas para defender su presencia en el currículum escolar (Tinning, 2012). En este contexto la EF se ofrece como un curso de acción paliativo a las consecuencias de la modernidad tardía en la que la salud ya no es una certeza, sino que se ha tornado vacilante y frágil. El estado delega en el individuo la responsabilidad por su salud, porque no se la va a proporcionar (Bauman, 2005). Se procura una racionalización de la cultura corporal para evitar emprender verdaderas políticas de incremento de la calidad de vida que afectarían a la hegemonía económica 
de los grupos de poder.

Las dos características descritas, eficientismo einstrumentalización, se evidencian en la práctica de la EF escolar. Por un lado, los estudios reflejan la importancia que los profesores le dan a los contenidos deportivos para desarrollar sus clases de EF (Robles, Giménez \& Abad, 2010; Robles, Abad, Castillo, Giménez \& Robles, 2013; Sicilia, SáenzLópez, Manzano \& Delgado, 2009). Por otro lado, otros estudios inciden en la función que la EF asume o debería asumir en la prevención de la obesidad infantil (Morano \& Colella, 2012; Oliveira \& dos Santos, 2006; Teldford, et al., 2012).

En los últimos años están surgiendo trabajos específicos que evidencian la escasa presencia del bloque de expresión corporal en la educación secundaria(Robles, etal., 2013; Villard, 2013)y quereivindican las posibilidades didácticas de las actividades en el medio natural «AMN» en los centros educativos (Arribas, et al., 2008; Baena \& Granero, 2008; Caballero, Sayago, Domínguez, Pérez \& Parra, 2006; Granero, Baena \& Martínez, 2010; Guillén \& Peñarrubia, 2013; Santos \& Martínez, 2011; Venero, 2007). Esta inquietud investigadora refleja el interés por incrementar la funcionalidad de la EF escolar, analizando si la práctica docente se corresponde con las finalidades que le han sido otorgadas por el sistema educativo. La funcionalidad se define como la capacidad de un sistema para ajustar sus objetivos y, a través de ellos, los productos, acciones y medios de que dispone, a las funciones que le han sido asignadas por la sociedad (De la Orden, 2009). Una docencia que sesga los bloques de contenidos no puede ser funcional.

Los libros de texto son inputs al sistema educativo, y por tanto deben ser productores de saberes, valores y modos de actuar coherentes con las finalidades del sistema educativo. No obstante, la desproporción que existe en los libros de texto entre los diferentes bloques de contenidos que establece el currículum de la EF ha sido puesta de manifiesto en diferentes investigaciones (Díaz, 2003; González, 2005; Táboas \& Rey, 2012). Todas ellas coinciden en afirmar el trato preferente que se les da a los contenidos de «Condición física y salud» y de «Juegos y deportes».

En el análisis realizado de las imágenes de los libros deEF publicados durantela Ley Orgánica 1/1990, de 3 de octubre, de Ordenación General del Sistema Educativo-LOGSE-se evidencióla mayor presencia de los deportes frente a otros contenidos y la superación del modelo de actividad física competitiva y de élite deportiva (Táboas \& Rey, 2012). Táboas y Rey (2012) ponen de manifiesto que el deporte es la actividad predominante en las imágenes de los libros de texto de EF de todas las editoriales que publicaron bajo la LOGSE. Los deportes constituyen el 45.39\% sobre el total de imágenes analizadas. Las prácticas no deportivas con mayor presencia en las fotografías son las actividades relacionadas con la mejora de la condición física, con un porcentaje del 13\%. Las AMN aparecen en $11.49 \%$ de las imágenes, las actividades artísticas en un $9.08 \%$, y los juegos en un porcentaje del $8.93 \%$. Hay editoriales que se alejan de la tendencia a mostrar escasamente las AMN. Santillana, Laberinto y Anaya dedican respectivamente a este tipo de actividades un $16.55 \%$, un $20.52 \%$ y un $26.57 \%$. Estas autoras también manifiestan que las fotografías representan actividades físicas en ámbitos competitivos en un $28.32 \%$ de los casos, mientras que las actividades realizadas en contextos educativos formales están presentes en un 14.91\% del total de imágenes. Con respecto al nivel de práctica las fotografías más frecuentes son las que reflejan prácticas alejadas del alto rendimiento.

El objetivo del trabajo es analizar si los libros de texto de EF publicados a partir de la LOE para la ESO, muestran desequilibrios en la representación de las diferentes actividades físicas que se proponen en los bloques de contenidos del currículo. Las hipótesis planteadas al respecto son: 1. En las imágenes de los libros de texto de EF de la ESO los deportes aparecen más representados que otros tipos de actividades físicas; 2. En las imágenes de los libros de texto de EF de la ESO predomina la representación de un modelo competitivo de actividad física frente a modelos educativos, informales, utilitarios, instrumentalizados o contextos escénicos; 3. Las imágenes de los libros de texto de EF representan mayoritariamente actividades alejadas de la élite deportiva frente a actividades de élite deportiva.

\section{Metodología}

El estudio es de tipo empírico, descriptivo y utiliza el análisis de contenido como técnica central de la investigación. Las fotografías editadas en los libros de texto de EF para la etapa de ESO son las unidades de muestreo.

\section{Muestra}

La selección de la muestra fue intencional o de conveniencia. Se analizaron dos editoriales a las que se tuvo fácil acceso, que cumplían los requisitos de ser una generalista «Anaya», otra con vinculación específica al área de EF «Bruño: Pila Teleña», y que habían editado manuales para los cuatro cursos de la ESO en el periodo 2007-2010. Se analizaron todas las fotografías presentes en los manuales de estas editoriales excepto en las que no aparecía la figura humana-dimensión cuerpo-y/ o en las que no se distinguía el tipo de actividad física. La muestra final

Tabla 1

Sistema de categoría

Categorías/Indicadores

2.1. Tipo de actividad física

2.1.1. Deportes balonmano, hockey, rugby, bés bol, waterpolo, polo o voleibol.
Deportes donde la participación es individual, sin compañeros/as que puedan 2.1.2. Deportes individuales perjudicar de forma directa al participante y todos aquellos deportes denominados tradicionalmente de adversario. Por ejemplo: natación, denominados tradicionalmente de adversario. Por ej emplo: natación,
atletismo, gimnasia, tenis, boxeo, jud o, golf, motocidismo o halterofilia. $\begin{array}{ll}\text { 2.1.3. Artísticas } & \text { ejemplo, las actividades relacionadas con mi mo, teat ro, dan za, baile o moda. } \\ \text { También se incoporan las imágenes que muestran la expresión facial o }\end{array}$ gestual como el objeto fundamental de la acción.
gesta

2.1.4. Fitness y Condición Actividades dirigid as a mejorar la fuerza, la velocidad, la flexibilidad o la Física a eróbic, spinning o aquagym. Actividades de valoración y/o medición tales como la toma de pul saciones u $\begin{array}{ll}\text { 2.1.5. Complementarias } & \begin{array}{l}\text { otras tareas propias de la cinean trop ometría -medición de pliegues, talla, } \\ \text { peso, etc- o delavaloración funcional-Course Navette, test de flexibilidad, }\end{array}\end{array}$ etc.-.
Actividades relacion adas directamente con la realización de movimientos y 2.1.6. De higiene postural la adopción de posturas típicas de la vida cotidi ana de la forma más adecuada \begin{tabular}{l} 
para disminui rel riesgo de padecer dolores, es pecialmentede espal da. \\
\hline 2.1.7. Actividades Físicas en \\
Actividades como parapente, puenting, ciclot uri smo, trekking, senderismo,
\end{tabular} el Medio Natural-AFMN- escalada, rutas a caballo, surf, rafting, etc.

2.1.8. Prácticas $\begin{array}{ll}\text { 2.1.8. Prácticas de } & \text { actividades físicas milenaria de origen oriental y otras de creación muy } \\ \text { interionización } & \text { reciente. Yoga, taichí, relajación, meditación, bi onenergética, eutonía, masaje, }\end{array}$ etc." (Olivera \& Olivera, 1995, p.17) Actividades que tienen como característica fundamental la aceptación libre de reglas sencillas, modificables y adaptadas al grupo. Se incluyen en este

\begin{tabular}{ll} 
2.1.9. Juegos & $\begin{array}{l}\text { indicador los denominados "juegos populares" - el escondite, el trompo, la } \\
\text { ll ave, etc.-; los nuevos juegos deportivos como el floorball, el ultimate o el } \\
\text { balonkorf; } y \text {, las diferentes modalidades de malabares. }\end{array}$ \\
\hline
\end{tabular}

\begin{tabular}{ll} 
2.1.9. Juegos & $\begin{array}{l}\text { indicador los denominados "juegos populares" - el escondite, el trompo, la } \\
\text { ll ave, etc.-; los nuevos juegos deportivos como el floorball, el ultimate o el } \\
\text { balonkorf; } y \text {, las diferentes modalidades de malabares. }\end{array}$ \\
\hline
\end{tabular}

\begin{tabular}{ll} 
2.1.9. Juegos & $\begin{array}{l}\text { indicador los denominados "juegos populares" - el escondite, el trompo, la } \\
\text { ll ave, etc.-; los nuevos juegos deportivos como el floorball, el ultimate o el } \\
\text { balonkorf; } y \text {, las diferentes modalidades de malabares. }\end{array}$ \\
\hline
\end{tabular} \begin{tabular}{ll}
\hline 2.1.10. Laborales & $\begin{array}{l}\text { Actividades pertenecie } \\
\text { cualquiert ipo de oficio. }\end{array}$
\end{tabular}

$\begin{array}{ll}\text { cualquiert ipo de oficio. } & \text { Actividades relacionadas con el cuidado y limpieza de la vivienda, la }\end{array}$ 2.1.11. Actividades de la preparación de alimentos, el lavado y plan chado de la ropa, así como Vida Diaria-AVD- movimientos corporales que forman parte de la vida cotidiana de cada persona. Por ejemplo: caminar, cargar objetos, subir escaleras o conducir. designado como "personas con necesidades educativas especiales". Es decir,

\begin{tabular}{l} 
2.1.12. Ad aptadas \\
$\begin{array}{l}\text { en la fotografía se observa que los individuos presentan una carencia a nivel } \\
\text { cerebral, con deficienciatectual - suj et os con síndrome de down, con parális sis }\end{array}$ \\
\hline
\end{tabular}

\begin{tabular}{l} 
2.1.12. Ad aptadas \\
$\begin{array}{l}\text { en la fotografía se observa que los individuos presentan una carencia a nivel } \\
\text { cerebral, con deficienciatectual - suj et os con síndrome de down, con parális sis }\end{array}$ \\
\hline
\end{tabular}

\begin{tabular}{l} 
2.1.12. Ad aptadas \\
$\begin{array}{l}\text { en la fotografía se observa que los individuos presentan una carencia a nivel } \\
\text { físico, sensorial o intelectual -suj etos con síndrome de down, con paráli sis } \\
\text { cerebral, con deficiencias en el aparato o locomotor, ciegos, etc.-. }\end{array}$ \\
\hline
\end{tabular} Actividades que no están incluidas en alguno de los indicadores anteriores o \begin{tabular}{ll} 
2.1.13. Otras & $\begin{array}{l}\text { Actividades que no est án incluidas en alguno de los indicadores anteriores o } \\
\text { imágenes en las que se representan dos o más actividades distintas, } \\
\text { pertenecientes a indicadores diferentes. }\end{array}$ \\
\hline Mediante la observación de la imagen no se puede discernir el tipo de
\end{tabular} \begin{tabular}{ll}
\hline 2.1.14. No se distingue & $\begin{array}{l}\text { Mediante la observación de la imagen no se puede discernir el tipo de } \\
\text { actividad física representada. }\end{array}$ \\
\hline 2.2. Ámbito
\end{tabular}

Actividades que perten ecen al ámbito de la compet ición institucionalizada. 2.2.1. Competitivo La presencia de árbitros, de un terreno de juego con las dimensiones resencia de espectadores/as pueden ser signos de tr contexto competitivo. Inagenes que se ubican en el ámbito de la educación. Incluye contextos $\begin{array}{ll}\text { 2.2.2. Educativos } & \text { educativos formales -un gimnasio de la escuela, el aula, el comedor o el } \\ \text { patio de recreo- y los educativos no formales -entrenamientos, grupos }\end{array}$ patio de recreo- $y$ los educativos no formales -entrenamientos, grupos
dinigidos por un monitor/a, un grup o u organización identificable, etc.-. Imágenes que representan la práctica de actividad física fuera del contexto educativo o competitivo y que son realizadas individualmente o entre
familiares, amigos, etc. Por ejemplo: un paseo por la playa, un partido de baloncesto en el parque, etc.
Imágenes que se incluyen en contextos utilitarios -lugares de trabajo, las tiend as, el hogar y hospitales-; contextos instru mentalizados - ejercicio en

\begin{tabular}{ll} 
2.2.3. Oros & $\begin{array}{l}\text { una sala de acondicionami ento físico, ses ión de aeróbic en una sala de usos } \\
\text { múltiples, etc.- y contextos escénicos -espectáculos ambulantes, des fil es, } \\
\text { fiestas populares o carnavales-. }\end{array}$ \\
\hline Mediante la observación de la imagen no se puede discemir el ámbit o o
\end{tabular}

\begin{tabular}{ll} 
2.2.3. Oros & $\begin{array}{l}\text { una sala de acondicionami ento físico, ses ión de aeróbic en una sala de usos } \\
\text { múltiples, etc.- y contextos escénicos -espectáculos ambulantes, des fil es, } \\
\text { fiestas populares o carnavales-. }\end{array}$ \\
\hline Mediante la observación de la imagen no se puede discemir el ámbit o o
\end{tabular}

\begin{tabular}{ll} 
2.2.3. Oros & $\begin{array}{l}\text { una sala de acondicionami ento físico, ses ión de aeróbic en una sala de usos } \\
\text { múltiples, etc.- y contextos escénicos -espectáculos ambulantes, des fil es, } \\
\text { fiestas populares o carnavales-. }\end{array}$ \\
\hline Mediante la observación de la imagen no se puede discemir el ámbit o o
\end{tabular}

2.2.4. No se distingue contexto en el que está ubicada la imagen.

2.3. Nivel

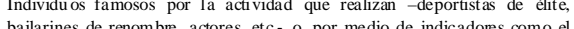
bailarines de renombre, actores, etc.- o, por medio de indicadores como el

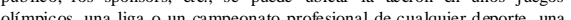

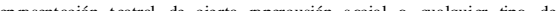
espectáculo de interés general. Individu os no famosos por la activi dad que realizan -deportistas de élite, sponsors, etc, por los que se puede ubicar la acción en unos juegos olímpicos, una liga o un campeonato profesional de culquier unos juegos olímpicos, una liga o un campeonato profesional de cualquier deporte, una
representación teatral de cierta repercusión social o aualquier tipo de espectáculo de interés general.

2.3.3. No se distingue Mediante la observación de la imagen no se puede discernir si los individuos Mediante la observación de la imagen no se puede discernir si los individuos
de la imagen perten ecen a la éli te de un deporte u otra actividad física o no. 
fue de ocho libros y un total de 539 imágenes fotográficas, 99 publicadas en Anaya, y 440 en Bruño: Pila Teleña.

\section{Variables}

Las variables que se presentan en este estudio son el tipo de actividad física, el ámbito de práctica y el nivel. La variable tipo de actividad física identifica y nomina las diferentes expresiones motrices que aparecen representadas en las imágenes. La variableámbito de práctica identifica y nomina el contexto o situación donde se realiza la actividad. Al hablar del contexto competitivo, educativo, instrumentalizado, escénico o utilitario, no se pretende indicar la finalidad con la que se realiza una determinada actividad física, ya que esto es imposible a través de la mera visualización de las fotografías. El ámbito no se diferencia únicamente por el espacio físico en el que se ubican las actividades sino por cuestiones relacionadas con el carácter específico de su práctica. La variable nivel identifica y nomina el grado de seriedad, entrega, dedicación y/o profesionalidad con la que se practica la actividad física.

En la Tabla 1 se explicitan las definiciones de los indicadores que operativizan cada una de las variables y que se aplicaron en el instrumento de análisis de contenido.

\section{Procedimiento}

Para efectuar el análisis de contenido de las imágenes se utilizó una adaptación del sistema de categorías para el análisis de las imágenes impresas en los libros de texto de EF de la ESO propuesto por Táboas (2009). Se modificó la categoría ámbito de práctica siguiendo las indicaciones de las conclusiones de su tesis doctoral, en las que apuntaba lanecesidad de «redefinir esta variable con la finalidad de obtenerresultados más precisos en próximos análisis» (p. 461). Para su elaboración ad hoc se comprobó la validez, fiabilidad, objetividad y utilidad práctica del instrumento de medición (Heinemann, 2003) antes de la recopilación final de los datos. Este proceso se organizó en dos fases:

1. Prueba piloto. Se llevó a cabo por la investigadora principal. Se escanearon y digitalizaron las imágenes de ocho libros de EF de fácil acceso. Se extrajo una muestra de 70 imágenes utilizando un muestreo aleatorio simple. Posteriormente, se codificaron las imágenes con el fin de revisar los conceptos, los elementos y la terminología del sistema de categorías. Con esta revisión se eliminaron problemas de comprensión y utilización de la herramienta. Este proceso piloto dio lugar a una leve reestructuración del sistema de categorías.

2. Consulta a expertos/as y triangulación con observadores/as. La consulta a expertos/as se efectuó durante el entrenamiento para la triangulación con observadores/as, ya que fueron ellos/as quienes participaron en la misma. Colaboraron en esta tarea de validación tres expertos/as en análisis de contenido vinculados al ámbito de las Ciencias de la Actividad Física y el Deporte. Durante el entrenamiento codificaron conjuntamente un total de 20 imágenes y la investigadora principal anotó las aportaciones que los expertos/as efectuaron sobre el sistema. Una vez terminada la sesión se corrigió el sistema de categorías y se envió para proceder a la triangulación.

La siguiente observación y codificación de las imágenes para la triangulación se realizó de forma individual, sobre un total de 50 imágenes. Se calculó la fiabilidad intercodificadores para averiguar el grado de acuerdo mediante el alfa de Krippendorff. Los valores (> .80) obtenidos en las diferentes categorías confirmaron la fiabilidad del sistema (Neuendorf, 2009): tipo de actividad física ( $a=.94)$, ámbito de práctica $(a=.90)$, nivel $(a=.92)$.

\section{Análisis y procesamiento de los datos}

Las imágenes se analizaron mediante observación directa del libro de texto. Aquellas fotografías que presentaron dudas acerca del tipo de actividad física representado en la imagen se codificaron a través de la información aportada por el texto o paratexto que las acompañaba. Se dividió el trabajo en varias sesiones para evitar errores por agotamiento de la observadora. El análisis estadístico se llevó a cabo con la ayuda del software SPSS 15.0 para Windows. Se realizó un análisis descriptivo univariante y comparativo entre grupos.

\section{Resultados}

Tipos de actividad física en los libros de texto de EF

La primera hipótesis de este estudio anticipaba que en las imágenes de los libros de texto de EF de la ESO los deportes aparecen más representados que otros tipos de actividades físicas. Los porcentajes de los resultados sobre la variable tipo de actividad física se obtienen de un $n=537$. Hay dos casos perdidos. El análisis de las imágenes muestra que el deporte es el tipo de actividad física predominante, ya que está presente en un 43.4\% de los casos. Los deportes individuales están presentes en 162 fotografías (30.2\%), y los deportes colectivos en 71 imágenes (13.2\%).

Las prácticas no deportivas que se representan en los libros de texto de EF son: actividades artísticas con 75 imágenes (14\% de los casos); las actividades de fitness y condición física y los juegos, con 57 imágenes cada una, lo que supone un $10.6 \%$ de la muestra respectivamente; y las $A F M N$ con 52 fotografías (9.7\% de los casos).

Determinados valores de la variable concentran pequeños porcentajes comparados con otros indicadores. Teniendo en cuenta esto, la Tabla 2 se construye a partir de la recodificación de los diferentes indicadores de la variable tipo e integrando en el indicador otras las actividades complementarias, las actividades de la vida diaria, las actividades laborales y las actividades físicas adaptadas. Tras esta nueva recodificación, los otros tipos de actividades se representan en 63 imágenes, conformando un $11.7 \%$ de la muestra total.

Las prácticas de interiorización y los ejercicios de higiene postural no presentan ningún resultado en las imágenes de los libros de texto de EF.

El análisis comparativo entre las dos editoriales analizadas muestra que ambas prestan mayor atención al bloque de contenidos de «Juegos y deportes». En Anaya está representado en un 43.8\% de las imágenes (42.8\% deportes y 1\% juegos) y en Bruño: Pila Teleña está representado en un $56.3 \%$ (43.5\% deportes y $12.8 \%$ juegos). Ambas editoriales presentan porcentajes similares en cuanto al bloque de «Expresión corporal». Anaya presenta un $11.2 \%$ de imágenes y Bruño: Pila Teleña un $14.6 \%$. Con respecto al bloque de AMN, los porcentajes entre ambas editoriales son muy dispares. La editorial Anaya presenta en un 21.4\% ese tipo de actividades mientras que Bruño: Pila Teleña tan sólo un 7.1\%. El bloque de «Condición física y salud», con porcentajes del 4.1\% para Anaya y del $12.1 \%$ para Bruño: Pila Teleña, es el menos representado. Los otros tipos de actividades están representadas en un 19.3\% en la editorial Anaya y en un 10\% en Bruño: Pila Teleña. (Véase Figura 1).

Ámbito de práctica de las imágenes de los libros de texto de EF

La segunda hipótesis de este estudio anticipaba que en las imágenes de los libros de texto de EF de la ESO predomina la representación de un modelo competitivo de actividad física frente a modelos educativos, informales, utilitarios, instrumentalizados o contextos escénicos.

Los resultados de la variable ámbito son obtenidos a partir de una

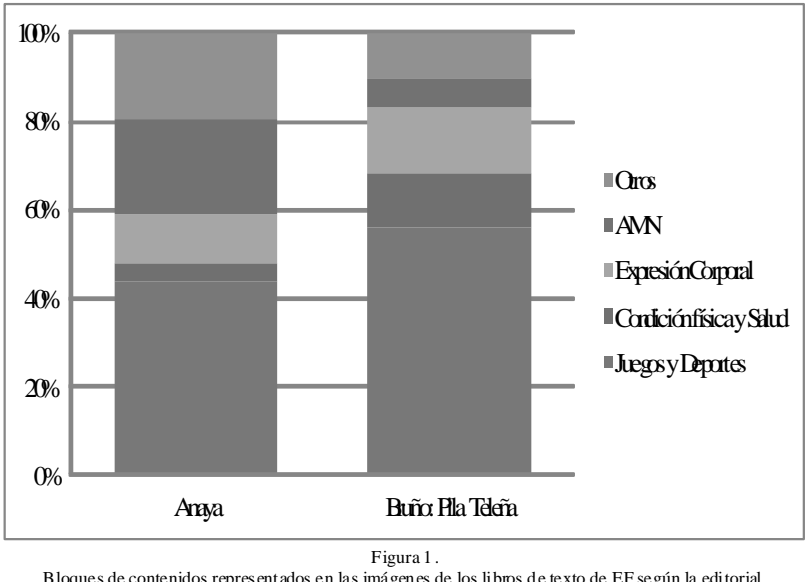


Tabla 2 .

Tabla 2.
Tipos de actividad física en las imágenes de los libros de texto de $\mathrm{E}$

\begin{tabular}{lcc}
\hline Tipo de actividad física & Frecuencia & Porcentaje \\
\hline Deportes & 162 & $43.4 \%$ \\
Artísticas & 75 & $14 \%$ \\
Fitness y Condición física & 57 & $10.6 \%$ \\
AFMN & 52 & $9.7 \%$ \\
Juegos & 57 & $10.6 \%$ \\
Orros & 63 & $11.7 \%$ \\
\hline
\end{tabular}

Tabla 3

Ámbitos de práctica en las imágenes de los libros de texto de

\begin{tabular}{lcc}
\multicolumn{2}{l}{ Ambitos de práctica en las imágenes de los libros de texto de EF } & \\
\hline Ámbito de prá́ctica & Frecuencia & Porcentaje \\
\hline Competitivo & 145 & $31.6 \%$ \\
Educativo & 138 & $30 \%$ \\
Informal & 122 & $26.6 \%$ \\
Orros & 54 & $11.8 \%$ \\
\hline
\end{tabular}
$11.8 \%$

Tabla 4

Niveles de práctica en las imágenes de los libros de texto de EF

Nivel 525 $2.1 \%$

muestra de 459 fotografías ( $n=459$ ). Existen 80 casos perdidos. Los resultados muestran que las prácticas realizadas en contextos competitivos (31.6\%) son las más presentes en las fotografías de los libros de texto. En el desglose por editoriales tanto Anaya (34.8\%) como Bruño: Pila Teleña (30.8\%) presentan porcentajes similares.

Las imágenes más representadas dentro del ámbito educativo son las que se ubican en prácticas no formales (18.7\%). Las actividades realizadas en centros educativos se representan en un $11.3 \%$. Este ámbito presenta diferencias entre ambas editoriales, Anaya presenta un $1.1 \%$ de imágenes en contextos formales, mientras que Bruño: Pila Teleña lo hace en un $13.8 \%$.

Las imágenes de los libros de texto representan actividades informales en un $26.6 \%$ de los casos. Con respecto a los otros ámbitos de práctica, los libros de texto muestran actividades relacionadas con el mundo escénico en un 7.4\%, prácticas utilitarias en un 3.5\% y actividades instrumentalizadas en un .9\% (Véase Tabla 3).

\section{Nivel de práctica de las imágenes de los libros de texto de EF.}

La tercera hipótesis de este estudio anticipaba que las imágenes de los libros de texto de EF representan mayoritariamente actividades alejadas de la élite deportiva frente a actividades de élite deportiva. Para esta variable el valor de $n$ es de 536. Hay tres casos perdidos. Las fotografías más representadas en los libros de texto de EF son las que reflejan prácticas alejadas del alto rendimiento(97.9\%). (Véase Tabla 4). En el análisis por editoriales, Anaya presenta un 90.7\% y Bruño: Pila Teleña un $99.5 \%$

Las actividades relacionadas con la élite deportiva se representan en un 2.1\% de la muestra total. El análisis de estas actividades según la editorial muestra diferencias entre ambas. Anaya las representa en un 9.3\% y Bruño: Pila Teleña en un .5\%.

\section{Discusión}

El análisis de los resultados de las imágenes de EF editadas bajo la LOE revela que no se han producido grandes cambios con respecto a las imágenes analizadas durante la ley de educación anterior.

La primera hipótesis de este estudio ha sido corroborada. En las imágenes de los libros de texto de EF de la ESO los deportes aparecen más representados que otros tipos de actividades físicas. Las imágenes continúan mostrando modelos de actividad física sesgados. Los deportes siguen manteniendo una representación hegemónica frente al resto de actividades físicas. Estos resultados coinciden con el estudio efectuado por Táboas y Rey (2012) en las imágenes de los libros de texto de EF publicados en la LOGSE.

Los resultados muestran que ambas editoriales otorgan más importancia al bloque de contenidos de «Juegos y deportes» que al resto de bloques planteados en el currículum de laEF escolar: «Condición física y salud», «Expresión corporal» $\mathrm{y}$ «Actividades en el medionatural». Estos datos son acordes con las investigaciones que analizan el desarrollo de contenidos en las aulas de EF (Sicilia, et al., 2009), y corroboran anteriores análisis de la presencia de los bloques contenidos en los libros de texto de EF (Díaz, 2003; González, 2005; Táboas \& Rey, 2012). A pesar de que las dos editoriales analizadas en el presente estudio centran sus imágenes en los deportes, la editorial Anaya continúa dándole más importancia que la editorial Bruño al bloque de AMN. Este aspecto es coincidente con los datos expuestos por Táboas y Rey (2012) al respecto de la edición de estos manuales durante el período LOGSE.

Los bloques de «Expresión corporal» y «Actividades en el medio natural» están relegados a una presencia considerablemente inferior en las imágenes de los libros de texto analizadas. El estudio llevado a cabo por Villard (2013) sobre las percepciones del profesorado de secundaria sobre el papel de la expresión corporal en el currículo de EF, manifiesta que los/as participantes coinciden en indicar que la expresión corporal es un contenido en condiciones de desigualdad con respecto a los contenidos considerados más tradicionales. En la misma línea, una encuesta realizada a los profesores de EF de secundaria de la provincia de Huelva evidenció que el bloque de «Expresión corporal» y el bloque de «Actividades en el medio natural» son los menos valorados por el profesorado (Robles, et al., 2013).

La segunda hipótesis de este estudio ha sido parcialmente corroborada. Si bien en las imágenes de los libros de texto de EF de la ESO predomina la representación de un modelo competitivo de actividad física frente a modelos educativos, informales, utilitarios, instrumentalizados o contextos escénicos; las dos editoriales analizadas incorporan altos porcentajes de imágenes en ámbitos informales. Este dato supone un cambio hacia modelos de práctica corporal diversificados y confirma los indicios apuntados por Táboas y Rey (2012) con respecto al distanciamiento de la reproducción mayoritaria de un modelo deportivo competitivo y elitista. La tendencia a la instrumentalización de la EF no se refleja en los contenidos visuales de los libros de texto. La tercera hipótesis, que anticipaba que las imágenes de los libros de texto de EF representan mayoritariamente actividades alejadas de la élite deportiva frente a actividades de élite deportiva, ha sido confirmada. Se obtuvo que el nivel de práctica más representado en ambas editoriales no es de alto rendimiento. Datos que corroboran los datos aportados por Táboas y Rey (2012) en el análisis de las imágenes de los libros de texto de EF de laLOGSE. Estas autoras observaron que en nueve de las 10 editoriales analizadas, el nivel predominante era el de no élite. Los datos del presente estudio son divergentes con lo hallado por Díaz (2003) en los materiales y textos de Secundaria para el área de EF.

\section{Conclusiones}

Las conclusiones del trabajo son cuatro. La primera es que no existen grandes cambios entre los libros de texto de EF publicados durante la vigencia de la LOGSE y los libros editados en la LOE con respecto a la representación de los diferentes bloques de contenidos presentados en el currículum de EF. La segunda es que los libros de texto de EF siguen centrando su atención en los contenidos relacionados con los deportes y ofrecen una visión sesgada del amplio abanico de expresiones motrices existentes. La tercera es que la representación de una EF ligada al mundo de la competición institucionalizada y a la élite deportiva parece estar dando paso a otros modelos de actividad física vinculada a contextos informales recreativos, y contextos educativos formales y no formales. La cuarta es que los datos ponen de relieve que la transmisión de una cultura corporal plural requiere la adopción de una postura crítica en la elección del material didáctico de la EF. Para ello el profesorado debe tener conocimiento del potencial referencial de la imagen fotográfica y de los contenidos que transmiten en la actualidad. Las editoriales deberían prestar más atención a las leyes y decretos que rigen las enseñanzas mínimas a la hora de elaborar los libros didácticos y, de esta forma elaborar libros más equilibrados en contenidos visuales de las diferentes expresiones motrices. Los contenidos visuales de los libros de texto de EF analizados no se ajustan a la normativa española en materia de educación. Los resultados ponen de manifiesto que no son acordes a lo que dispone la LOE en su disposición adicional cuarta porque no se adecuan al currículo.

La EF escolar no debería sucumbir a un planteamiento sesgado destinado a la búsqueda de cuerpos operativos, bellos y fuertes. Es imprescindible desarrollar la función que esta asignatura tiene en el 
currículo para educar en, sobre y a través del movimiento (Kirk, 1990), pero siempre bajo los principios que establece la educación general. Entre ellos el establecido en el artículo 1 de la ley de educación vigente «la transmisión y puesta en práctica de valores que favorezcan la libertad personal, la responsabilidad, la ciudadanía democrática, la solidaridad, la tolerancia, la igualdad, el respeto y la justicia, así como que ayuden a superar cualquier tipo de discriminación».

El presente estudio está limitado a dos editoriales, por lo que es necesario ampliar el análisis a un mayor número de editoriales para conocer si esta tendencia ocurre en todas.

\section{Referencias}

Arribas, H., Blas, D., Cabanas, V., de las Heras, A., Flórez, E., \& Talegón, J. (2008). Un puerta (entre) abierta: oportunidades educativas en el medio natural. Ágora para la EF y el Deporte, 7-8, 7-34. Recuperado de http://www5.uva.es/agora/revista/7/ agora7-8_arribas_1.pdf

Baena, A., \& Granero, A. (2008). Las actividades físicas en la naturaleza en el currículum actual: contribución a la educación para la ciudadanía y los derechos humanos. Retos. Nuevas tendencias en Educación Física, Deporte y Recreación, 14, 48-53. Recuperado de http://www.retos.org/numero_14_13/retos\%2014-8.pdf

Barbero, J. I. (1996). Cultura profesional y currículum (oculto) en educación física. Reflexiones sobre las (im)posibilidades del cambio. Revista de educación, 311, 1349.

Bauman, Z. (2005). Modernidad líquida. Buenos Aires: Fondo de Cultura Económica de Argentina.

Caballero, P., Sayago, D., Domínguez, G., Pérez, O., \& Parra, M. (2006). Jugando en un espacio de fantasía. Claves para elaborar una jornada de aventura en un centro de enseñanza. Retos. Nuevas tendencias en Educación Física, Deporte y Recreación, 10, 23-30. Recuperado de http://www.retos.org/numero_9_10/retos10-2.pdf

Camacho-Miñano, M. J., Fernández, E., Ramírez, E., \& Blández, J. (2013). La Educación Física escolar en la promoción de la actividad física orientada a la salud en la adolescencia: una revisión sistemática de programas de intervención. Revista Complutense de Educación, 24(1), 9-26. doi:10.5209/ rev RCED.2013.v24.n1.41189

Canales, I., \& Rey, A. (2008). Deporte y dualismo: su influencia en la educación física escolar. Revista Española de Educación Física y Deporte, 9, 89-102.

De la Orden, A. (2009). Evaluación y calidad: análisis de un modelo. Estudios sobre Educación, 16, 17-36.

Díaz, B. (2003). Los libros de texto como instrumentos de deportivización del currículo real de la Educación Física. Revista Digital Lecturas: Educación Física y Deportes. Revista digital, 56. Recuperado de http://www.efdeportes.com/efd56/texto.htm

Europapress (27 de noviembre de 2012). Sanidad propone a Educación implantar una hora diaria de ejercicio físico en los colegios. Recuperado de http:/ www.europapress.es/salud/noticia-sanidad-propone-educacion-implantar-horadiaria-ejercicio-fisico-colegios-20121127154050.html

Foucault, M. (1992). Microfísica del poder.Madrid: La Piqueta.

González, M. (2005). ¿Tienen sexo los contenidos de la Educación Física Escolar? Transmisión de estereotipos de sexo a través de los libros de texto en la etapa de secundaria. Revista internacional de Medicina y Ciencias de la Actividad Física y el Deporte, 5(18), 77-88. Recuperado de http://cdeporte.rediris.es/revista/ revista18/artsexismo8.htm

Granero, A., Baena, A., \& Martínez, M. (2010). Contenidos desarrollados mediante las Actividades en el Medio Natural de las clases de Educación Física en Secundaria Obligatoria. Ágora para la EF y el Deporte, 12(3), 273-288. Recuperado de http: /www5.uva.es/agora/revista/12_3/agora12_3c granero_et_al

Guillén, R., \& Peñarrubia, C. (2013). Incorporación de contenidos de Actividades en el Medio Natural mediante la investigación-acción colaborativa. Retos. Nuevas tendencias en Educación Física, Deporte y Recreación, 23, 23-28. Recuperado de http://www.retos.org/numero_23/23-28.pdf

Heinemann, K. (2003). Introducción a la metodología de la investigación empírica en las ciencias del deporte. (1 $1^{\mathrm{a}}$ ed.) Barcelona: Paidotribo.

Kirk, D. (1990). Educación física y currículum: introducción crítica. Valencia: Universitat de Valencia. Servei de publicacions.

Kogan, L. (2003). La construcción social de los cuerpos o los cuerpos del capitalismo tardío. Persona, 6, 11-21. Recuperado de http://www.redalyc.org/ articulo.oa?id=147118110001

Lagardera. F. (1992). Introducción de la Gimnástica en el Sistema Educativo Españo (De práctica aristocrática a su transformación en praxis deportiva en el marco de una sociedad decimonónica en busca de la modernidad). En International Standing Conference for the History of Education. Education, physical activities and sport in a historical perspective (pp. 82-93). Barcelona: Secretaría General del Deporte.

Ley Orgánica 2/2006, de 3 de mayo, de Educación, 106 B.O.E., 17158-17207 (4 de mayo de 2006).

Ley Orgánica 8/2013, de 9 de diciembre, para la mejora de la calidad educativa, 295 B.O.E., 97858-97921 (10 de diciembre de 2013).

Martínez, J. (2002). Políticas del Libro de Texto Escolar. Madrid: Ediciones Morata.

Ministerio de Sanidad, Servicios Sociales e Igualdad (27 de mayo de 2014). Sanidad apuesta por actuar en el ámbito escolar para prevenir la obesidad infantil y fomentar los hábitos de vida saludables. Recuperado de https:// www.msssi.gob.es/gabinete/notasPrensa.do?id=3300

Molina, J.P., Devís, J., \& Peiró, C. (2008). Materiales curriculares: Clasificación y uso en Educación Física. Pixel-Bit. Revista de Medios y Educación, 33, 183-197.

Morano, M., \& Colella, D. (2012). Physical activity for the prevention of childhood obesity: an overview of key research challenges for physical education. Acto Facultatis Educationis Physicae Universitatis Comenianae, 52(2), 49-59. Recuperado de http://web.b.ebscohost.com/ehost/pdfviewer/ pdf vi e wer ? sid = f 8 a $81 \mathrm{~d} 7 \mathrm{f}-3 \mathrm{~d} 04-469 \mathrm{f}-9152$ 29c53de5b39e\%40sessionmgr112\&vid=18\&hid $=121$
Moray, M. L. (2010). El Libro de Texto Escolar Didáctico y El Material Literario Auténtico. Una mirada a la cultura material de la escuela. Recuperado de http:/ www.educared.org.ar/biblioteca/coordenadas/files/moray2010.pdf.

Neuendorf, K. A. (2009). Reliability for Content Analysis. En A. B. Jordan, D. Kunkel, J. Manganello \& M. Fishbein (eds.), Media Messages and Public Health: A Decisions Approach to Content Analysis (pp 67-87). Nueva York, NY: Routledge.

Oliveira, J., \& dos Santos, A. (2006). A prática de atividade física entre escolares com sobrepeso e obesidade. Revista Mackenzie de Educaçao e Esporte, 5(especial), 47-54. Recuperado de http://editorarevistas.mackenzie.br/index.php/remef/article/ viewFile/1896/1368

Olivera, J., \& Olivera, A. (1995). La crisis de la modernidad y el advenimiento de la posmodernidad: el deporte y las prácticas físicas alternativas en el tiempo de ocio activo. Apunts: educación física y deportes, 41, 10-29. Recuperado de http:// www.revista-apunts.com/es/hemeroteca?article $=812$

Pringle, R., \& Pringle, D. (2012). Competing obesity discourses and critical challenges for health and physical educators. Sport, Education \& Society 17(2), 143-161. doi: 10.1080/13573322.2011.607947

Proyecto de Ley Orgánica para la mejora de la calidad educativa. (621/000048). Enmiendas del senado mediante mensaje motivado, 275 B.O.C.G.D., 60-169 (27 de noviembre de 2013).

Puig, N., \& Heinemann, K. (1991). El deporte en la perspectiva del año 2000. Papers. Revista de Sociología, 38, 123-141. Recuperado de http://ddd.uab.es/pub/papers/ 02102862n38/02102862n38p123.pdf

Real Decreto 1631/2006, de 29 de diciembre, por el que se establecen las enseñanzas mínimas correspondientes a la Educación Secundaria Obligatoria, 5 B.O.E., 677733 (5 de enero de 2007)

Robles, J., Abad, M. T., Castillo, E., Giménez, F. J., \& Robles, A. (2013). Factores que condicionan la presencia de la expresión corporal en la enseñanza secundaria según el profesorado de educación física. Retos. Nuevas tendencias en Educación Física, Deporte y Recreación, 24, 171-175. Recuperado de http://www.retos.org/ numero 24/171-175.pdf

Robles, J., Giménez, F.J., \& Abad, M. T. (2010). Motivos que llevan a los profesores de Educación Física a elegir los contenidos deportivos en la E.S.O. Retos. Nuevas tendencias en Educación Física, Deporte y Recreación, 18, 5-8. Recuperado de http://www.retos.org/numero_18/RETOS18-1.pdf

Santos, Ma. L., \& Martínez, L.F. (2011). Aprendizaje integrado de las actividades en el medio natural desde las competencias en la ESO. Tándem: Didáctica de la Educación Física, 36, 53-60.

Santos, S. (2005). La Educación Física escolar ante el problema de la obesidad y el sobrepeso. Revista Internacional de Medicina y Ciencias de la Actividad Física y del Deporte, 5(19), 179-199. Recuperado de http://www.redalyc.org/ articulo oa?id $=54221996003$

Sicilia, A., Sáenz-López, P., Manzano, J.I., \& Delgado, M.A. (2009). El desarrollo curricular de la Educación Física en Primaria y Secundaria: un análisis desde la perspectiva del profesorado. Apunts: Educación física y deportes, 98, 23-32.

Táboas, Ma. I. (2009). Análisis de los estereotipos corporales y de los modelos de actividad física representados en las imágenes de los libros de texto de Educación Física. (Tesis doctoral). Universidade de Vigo. Pontevedra.

Táboas, Mª.I., \& Rey, A. (2012). Los contenidos de la Educación Física en Secundaria: un análisis de las actividades físicas que se enseñan desde las imágenes de los libros de texto. Apunts. Educación Física y Deportes, 107, 45-73. doi: 10.5672/ apunts.2014-0983.es.(2012/1).107.04

Teldford, R.D., Cunningham, R.B., Fitzgerald, R., Olive, L.S., Prosser, L., Jiang, X., \& Teldford, R.M. (2012). Physical Education, Obesity, and Academic Achievement: A 2-Year Longitudinal Investigation of Australian Elementary School Children. American Journal of Public Health, 102(2), 368-374. Recuperado de http:// web.b.ebscohost.com/ehost/pdfviewer/pdfviewer?sid=f8a81d7f-3d04-469f9152-29c53de5b39e\%40sessionmgr112\&vid=18\&hid=12

Tinning, R. (2012). The idea of physical education: a memetic perspective. Physical Education and Sport Pedagogy, 17(2), 115-126. doi: 10.1080 / 17408989.2011.582488

Venero, J.P. (2007). La clase de Educación Física como motor de cambio social. Reflexionando sobre actividades en la naturaleza, currículum oculto y valores. Retos. Nuevas tendencias en Educación Física, Deporte y Recreación, 11, 51-53. Recuperado de http://www.retos.org/numero_11_12/retos\%2011-9.pdf

Villard, M. (2013). Percepciones de profesorado de secundaria sobre el papel de la expresión corporal en el currículo de la educación física. Tándem: Didáctica de la Educación Física, 42, 80-89. Recuperado de http://www.grao.com/revistas/tandem/042-quese-hace-en-educacion-fisica-en-otros-contextos/percepciones-del-profesorado-desecundaria-sobre-el-papel-de-la-expresion-corporal-en-el-curriculo-de-educacionfisica

Walder, P. (2004). El cuerpo fragmentado. Polis. Revista Latinoamericana, 7, 2-16. doi: $10.4000 /$ polis. 6278

World Health Organitation (Mayo, 2002). Resolution WHA53.23. Diet, physical activity and health. En: Fifty-fifth World Health Assembly. Geneva. Recuperado de http:/ /apps.who.int/gb/archive/pdf_files/WHA55/ewha5523.pdf

\section{Notas al pie}

${ }^{1}$ En el discurso de este trabajo se ha decidido adoptar la denominación Actividades en el Medio Natural «AMN» porque es la que se emplea en el bloque de contenidos perteneciente al currículo de EF de la ESO. El término que se emplea en el sistema de categorías para el análisis de las imágenes es el de Actividades Físicas en el Medio Natural «AFMN» porque recoge con mayor especificidad las manifestaciones motrices específicas desarrolladas en el medio natural.

${ }^{2}$ Este indefinición provocó que el Foro Profesional de las Ciencias del Deporte instase en el Senado una enmienda parcial, para que en la redacción de la mencionada disposición figurase «en los términos y condiciones que, siguiendo las recomendaciones de los organismos competentes, garanticen un desarrollo adecuado para favorecer una vida activa, saludable y autónoma. El diseño, coordinación y supervisión de las medidas que a estos efectos se adopten en el centro educativo, serán asumidos por el profesorado con cualificación o especialización adecuada en estos ámbitos» (Proyecto de Ley Orgánica para la mejora de la calidad educativa, 2013, p. 160) 